(2) Open Access Full Text Article

\title{
Doctors' knowledge, attitudes, and compliance with 20/3 ACC/AHA guidelines for prevention of atherosclerotic cardiovascular disease in Singapore
}

\author{
This article was published in the following Dove Press journal: \\ Vascular Health and Risk Management \\ 4 June 2015 \\ Number of times this article has been viewed
}

\author{
Sajita Setia' \\ Selwyn Sze-Wang Fung ${ }^{2}$ \\ David D Waters ${ }^{3}$ \\ 'Medical Affairs, Pfizer Pte Ltd, \\ Singapore; ${ }^{2}$ Regional Medical \\ Affairs, Pfizer Pte Ltd, Hong Kong; \\ ${ }^{3}$ Department of Medicine, University \\ of California, San Francisco, CA, USA
}

Correspondence: Sajita Setia

Medical Affairs, Pfizer Pte Ltd, I, Science

Park Road \# 04-0I, The Capricorn,

Science Park II, Singapore I I7528,

Singapore

Tel +65 64038754

Fax +65 67224188

Email sajita.setia@pfizer.com
Purpose: There is an unmet need for strategies to prevent atherosclerotic cardiovascular disease in Singapore. The main objective of this study was to investigate Singapore physicians' response to the 2013 American College of Cardiology and American Heart Association (ACC/AHA) guidelines for treatment of cholesterol and their impact on clinical practice.

Methods: This survey was conducted in two stages, qualitative and quantitative. Physicians were initially screened on the basis of an initial screener questionnaire, and eligible physicians were then included in the study.

Results: Qualitative ( $\mathrm{n}=19)$ and quantitative $(\mathrm{n}=66)$ surveys were completed by eligible physicians from Singapore. Physicians were less familiar with the 2013 ACC/AHA guidelines (35\%) as compared with the Singapore Ministry of Health (MoH) lipid guidelines 2006 (49\%). Of the physicians whose opinion was sought on the ACC/AHA guidelines, more than $50 \%$ disagreed with the definition of high-, moderate-, and low-intensity statin therapy; recommendation of atorvastatin $40-80 \mathrm{mg}$ and rosuvastatin $20-40 \mathrm{mg}$ as medications for high-intensity statin therapy; and classification of individuals who would benefit from moderate- to high-intensity statin therapy. Most physicians assumed that Asians may be intolerant to high-intensity statin therapy.

Conclusion: Although embracing the 2013 ACC/AHA guidelines in clinical practice is expected to provide better clinical care to patients, our study revealed high reluctance by physicians, especially in the use of high-dose statins. However, ACC/AHA guidelines can be easily adopted in Asia as there is a wealth of data available for atorvastatin in primary and secondary prevention of atherosclerotic cardiovascular disease with similar efficacy and safety profiles in the white and Asian populations.

Keywords: cholesterol treatment, cardiovascular disease, statin therapy, CVD risk factors, LDL target levels

\section{Introduction}

Cardiovascular diseases (CVDs) are the leading cause of death worldwide. ${ }^{1}$ According to a World Health Organization (WHO) report, CVDs contributed to 31\% (17.5 million) of global deaths in 2012, of which 7.4 million were estimated due to coronary heart disease (CHD) and 6.7 million due to stroke. Annual CVD deaths are projected to reach 22.2 million in $2030 .^{2}$ The CVD burden in Asia is rising, and half of the world's CVD is predicted to occur in this area. ${ }^{3}$ CVDs are the second most common cause of death in Singapore, with $29.6 \%$ deaths in $2013 .{ }^{4}$ Risk factors for CVD, such as diabetes and obesity, have been on the rise throughout Asia, including Singapore. From 2004 to 2010, 
there has been an increase in the diabetic population from $8.2 \%$ to $11.3 \% .^{5,6}$ Dyslipidemia, a lipoprotein metabolism disorder, is also a well-established risk factor for CVD. ${ }^{7,8}$ In 2010 , approximately $17 \%$ of adults aged $18-69$ years in Singapore had high total cholesterol levels ( $\geq 6.2 \mathrm{mmol} / \mathrm{L})$, $15.2 \%$ had high levels of low-density lipoproteins cholesterol (LDL-C) $(\geq 4.1 \mathrm{mmol} / \mathrm{L})$, and $10.8 \%$ had obesity. ${ }^{5,9}$ There is an unmet need for strategies to prevent CVD in Singapore. Most CVD could be prevented, and the deaths due to CVD could be reduced by addressing the modifiable risk factors; these factors are the same in almost all geographic regions and in every racial/ethnic group worldwide and are consistent in both sexes. ${ }^{10,11}$

The Adult Treatment Panel (ATP) created by the National Institutes of Health's National Cholesterol Education Program (NCEP) has been framing and revising guidelines to enable clinicians to deliver better treatment to cardiovascular patients and to educate the general public. The ATP III revision released in 2004 emphasizes intensive treatment of patients with CHD; in addition, it focuses on primary prevention in persons with multiple risk factors. ${ }^{12,13}$ Studies conducted after this revision suggested improved lipid management compared with previous surveys, but still showed significant underachievement of LDL-C goals. ${ }^{13-15}$

The Singapore Ministry of Health $(\mathrm{MoH})$ Clinical Practice Guidelines for lipids were last updated in 2006. Although now considered withdrawn, they also recommended the optimization of LDL-C level as the first priority for the prevention of $\mathrm{CHD}$ and treatment with statins for lowering high LDL-C levels. ${ }^{16}$

The National Heart, Lung, and Blood Institute (NHLBI), in collaboration with the American College of Cardiology (ACC) and the American Heart Association (AHA), released the revised cholesterol management guidelines in $2013 .{ }^{17}$ The 2013 ACC/AHA guidelines for cholesterol treatment have a broader focus on risk of atherosclerotic cardiovascular disease (ASCVD) including stroke, and identify four statin benefit patient groups that benefit from either "high-intensity" or "moderate-intensity" statin therapy rather than LDL-C or nonHDL-C targets. The four major statin benefit patient groups include 1) individuals with clinical ASCVD; 2) primary elevations of LDL-C $>190 \mathrm{mg} / \mathrm{dL}$; 3) diabetics aged 40-75 years with LDL-C 70-189 mg/dL and without clinical ASCVD; and 4) without clinical ASCVD or diabetes with LDL-C 70-189 $\mathrm{mg} / \mathrm{dL}$ and estimated 10-year ASCVD risk $\geq 7.5 \%$. Highintensity statin therapy (atorvastatin $40-80 \mathrm{mg}$ or rosuvastatin $20-40 \mathrm{mg}$ ) is recommended for most of these patients, and moderate-intensity statins for the remaining groups. ${ }^{17}$ The new 2013 ACC/AHA guidelines match statin assignment to total plaque burden better than the older guidelines, with only a modest increase in the number of patients who were assigned statins rather than relying on treating patients until arbitrary lipid target levels are achieved. ${ }^{18}$ Focusing on CVD risk rather than on LDL target levels makes this a new standard of care. If these guidelines are widely adopted, they could lead to much greater CV event reduction.

The current study was conducted mainly to investigate Singapore physicians' response to the 2013 ACC/AHA guidelines for treatment of cholesterol and its impact on their clinical practice. In addition, the study was also aimed to understand 1) concomitant conditions that may affect the choice of statins in clinical practice, 2) physicians' perceptions and habits with regard to the use of high-intensity statins, and 3 ) their considerations while choosing drugs for dyslipidemia.

\section{Materials and methods}

This cross-sectional survey was conducted among physicians in Singapore from February to May 2014. Surveys were conducted according to the globally accepted standards of good clinical practice (as defined in the International Conference on Harmonisation [ICH] E6 Guidelines for Good Clinical Practice, May 1, 1996) in agreement with the latest version of the Declaration of Helsinki and in accordance with the local internal and external regulations.

This study was conducted in two stages: a qualitative and a quantitative stage. Physicians were initially screened on the basis of an initial screener questionnaire (separate for the two stages), and according to the information provided by the physicians, those eligible were then included in the study. The physicians participating in this study were general practitioners (GPs), cardiologists, endocrinologists, and nephrologists (only in the quantitative module). The eligibility criteria for the two stages are presented in Table 1.

The qualitative module was conducted using a combination of online (Computer Assisted Web Interviews [CAWI]) and face-to-face (Computer Assisted Personal Interviews [CAPI]) interviews for 45 minutes. The quantitative module used a combination of CAWI and CAPI for 30 minutes that included questions that helped in the quantification of the qualitative findings. The CAWI was a self-administered interview, and CAPI was administered by an interviewer. The interview questions from the two modules helped answer the 
Table I Eligibility criteria for physicians to be included in the qualitative and quantitative surveys

Eligibility criteria

Qualitative survey

- Seen 30 or more patients in the past month

- Spent $50 \%$ or more time in a private setting

- Prescribed branded atorvastatin and rosuvastatin in the past 12 months

- Prescribed cholesterol-lowering medications to at least five (in the case of GPs) to 20 (in the case of cardiologists, endocrinologists) patients in the past month

- In the case of GPs, to have practiced between 3 and 30 years (inclusive)

- Cardiologists and endocrinologists had personally made decisions about dyslipidemia treatment for patients

Quantitative survey

- Required to have at least 3 years of clinical practice

- Prescribed cholesterol-lowering medications to at least 50 patients in the past month

- Personally made decisions about dyslipidemia treatment for patients

- Not working with a pharmaceutical company or health care manufacturer, serving as a clinical investigator, conducting clinical research, or providing consulting services in any paid capacity

Abbreviation: GPs, general practitioners.

four study objectives mentioned in the introduction section. The qualitative survey included questions from three broad categories - 1) patient workload; 2) patient journey and role of the physician and; 3 ) disease management and factors impacting prescription behavior. The quantitative survey included questions from six broad categories: treatment guideline familiarity and preference to treat dyslipidemia (mainly ACC/AHA 2013, NCEP ATP III, Singapore MOH, and European Society of Cardiology [ESC] guidelines 2012), patient workload, current drug awareness and preference, current drug usage trends (mainly pertaining to $2013 \mathrm{ACC} / \mathrm{AHA}$ guidelines for the treatment of blood cholesterol), preference for drug brand, and participant demographics (age).

\section{Statistical analysis}

Responses to various questions were tabulated. The statistical analysis was performed using the SPSS Statistics 20. Categorical variables were expressed as percentages, and continuous variables were expressed as mean values. Responses to questions from the qualitative interviews were summarized using content-analysis, and quantitative responses were summarized using descriptive statistics (as numbers and percentages).

\section{Results}

A total of 314 physicians were approached ( 82 for the qualitative survey and 232 for the quantitative survey);
85 physicians consented to participate and completed the interview (overall response rate: $27 \%$ ). The qualitative survey was completed by 19 eligible physicians (response rate: $23 \%$ ) and the quantitative survey by 66 eligible physicians (response rate: $28 \%$ ) from Singapore. For the qualitative survey, there were an equal number of GPs and cardiologists ( $\mathrm{n}=7$ each) followed by endocrinologists $(n=5)$ who participated in the survey. For the quantitative survey, most of the participants were GPs $(n=31)$ followed by cardiologists $(n=20)$, endocrinologists $(n=10)$, and nephrologists $(n=5)$.

\section{Awareness of 2013 ACC/AHA guidelines for the treatment of blood cholesterol}

Singapore physicians were less familiar with the 2013 ACC/ AHA guidelines (35\%) as compared with the Singapore $\mathrm{MoH}$ lipid guidelines 2006 (49\%). The percentage of physicians familiar with the 2001 NCEP ATP III guidelines (39\%) was little more than those familiar with the 2013 ACC/AHA guidelines, while the familiarity with ESC 2012 guidelines was only $15 \%$.

Familiarity with 2013 ACC/AHA guidelines was more prominent among the cardiologists $(65 \%)$ than among the endocrinologists/nephrologists (26\%) or the GPs (19\%). A similar trend was seen in the familiarity with the 2001 NCEP ATP III guidelines. Most of the GPs (58\%) followed by cardiologists (45\%), and endocrinologists/nephrologists (34\%) were very familiar with the Singapore $\mathrm{MoH}$ lipid guidelines 2006 .

\section{Awareness on the components of 20 I 3 ACC/AHA guidelines}

The views of 19 physicians (five endocrinologists, seven cardiologists, and seven GPs) were sought on the recommendations and statements made in the 2013 ACC/AHA guidelines

(Table 2). More than $50 \%$ of them disagreed with:

- the definition of high-, moderate-, and low-intensity statin therapy;

- recommendation of atorvastatin 40-80 mg and rosuvastatin $20-40 \mathrm{mg}$ as medications for high-intensity statin therapy; and

- classification of individuals who would benefit from moderate- to high-intensity statin therapy.

More physicians were in agreement with the guidelines that there is a lack of data supporting the use of nonstatin drugs combined with statin therapy for the reduction in 
Table 2 Physicians' agreement with statements from $2013 \mathrm{ACC} /$ AHA guidelines (results from qualitative stage)

\begin{tabular}{|c|c|c|c|}
\hline \multirow[t]{2}{*}{ Parameters } & \multicolumn{3}{|c|}{$\begin{array}{l}\text { Number of physicians } \\
(n=19) \text { who: }\end{array}$} \\
\hline & Agree & Disagree & $\begin{array}{l}\text { Remain } \\
\text { neutral }\end{array}$ \\
\hline $\begin{array}{l}\text { Definition of high-intensity, } \\
\text { moderate-intensity, and } \\
\text { low-intensity statin therapy }\end{array}$ & 7 & 11 & 1 \\
\hline $\begin{array}{l}\text { Atorvastatin } 40-80 \mathrm{mg} \text { and } \\
\text { rosuvastatin } 20-40 \mathrm{mg} \text { as the } \\
\text { medication of high-intensity statin } \\
\text { therapy }\end{array}$ & 9 & 10 & - \\
\hline $\begin{array}{l}\text { Four groups of individuals } \\
\text { would benefit from moderate- } \\
\text { to high-intensity statin therapy }\end{array}$ & 8 & 11 & - \\
\hline $\begin{array}{l}\text { No data supporting the routine use } \\
\text { of nonstatin drugs (eg, ezetimibe) } \\
\text { combined with statin therapy to } \\
\text { further reduce ASCVD events }\end{array}$ & 10 & 8 & 1 \\
\hline
\end{tabular}

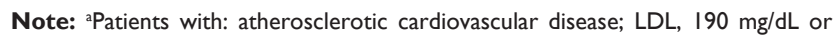
higher; high-risk T2D aged 40-75 years; 10-year risk of CVD $\geq 7.5 \%$, 40-75 years. Abbreviations: ACC/AHA, American College of Cardiology and American Heart Association; ASCVD, atherosclerotic cardiovascular disease; CVD, cardiovascular disease; LDL, low-density lipoprotein; T2D, type 2 diabetes.

ASCVD. However, they also believed that Asians may be intolerant to high-intensity statin therapy.

\section{Type of patients seen by the physicians participating in the survey} Physicians in this survey treated an average of 384 dyslipidemic patients, each in a period of 3 months. The majority of the patients ( $82 \%)$ had one or more concomitant illnesses. The most common co-morbidities were hypertension (57\%) and diabetes (52\%) followed by CHD (31\%), chronic kidney disease (CKD) (18\%), acute coronary syndrome (ACS) $(15 \%)$, and a history of stroke (12\%).

\section{Statin prescription behavior and pattern}

Most patients (91\%) with dyslipidemia along with a concomitant illness, and $67 \%$ of dyslipidemia patients without concomitant illness were prescribed statins. Of the patients with dyslipidemia and diabetes, $90 \%$ were on statins, while $79 \%$ of those with dyslipidemia and hypertension received statins.

Atorvastatin, rosuvastatin, and simvastatin were the three major statins prescribed to dyslipidemia patients with a concomitant illness. Rosuvastatin was predominantly prescribed for CHD and ACS (Figure 1).

Prescription of high-intensity atorvastatin (40 and 80 $\mathrm{mg}$ ) and rosuvastatin (20 and $40 \mathrm{mg}$ ) was considerably less as compared with moderate-intensity atorvastatin (10 and $20 \mathrm{mg}$ ) and rosuvastatin $(10 \mathrm{mg})$, respectively. Overall, only $7 \%$ of total dyslipidemia patients were prescribed $40 \mathrm{mg}$ atorvastatin and $1 \%$ were prescribed $80 \mathrm{mg}$ atorvastatin while $19 \%$ were prescribed $20 \mathrm{mg}$ rosuvastatin and $1 \%$ were prescribed $40 \mathrm{mg}$ rosuvastatin.

Applying the 2013 ACC/AHA guidelines, a considerable number of patients would be eligible for treatment with highintensity statins. However, less than $50 \%$ of such patients were prescribed high-intensity statins (Table 3 ).

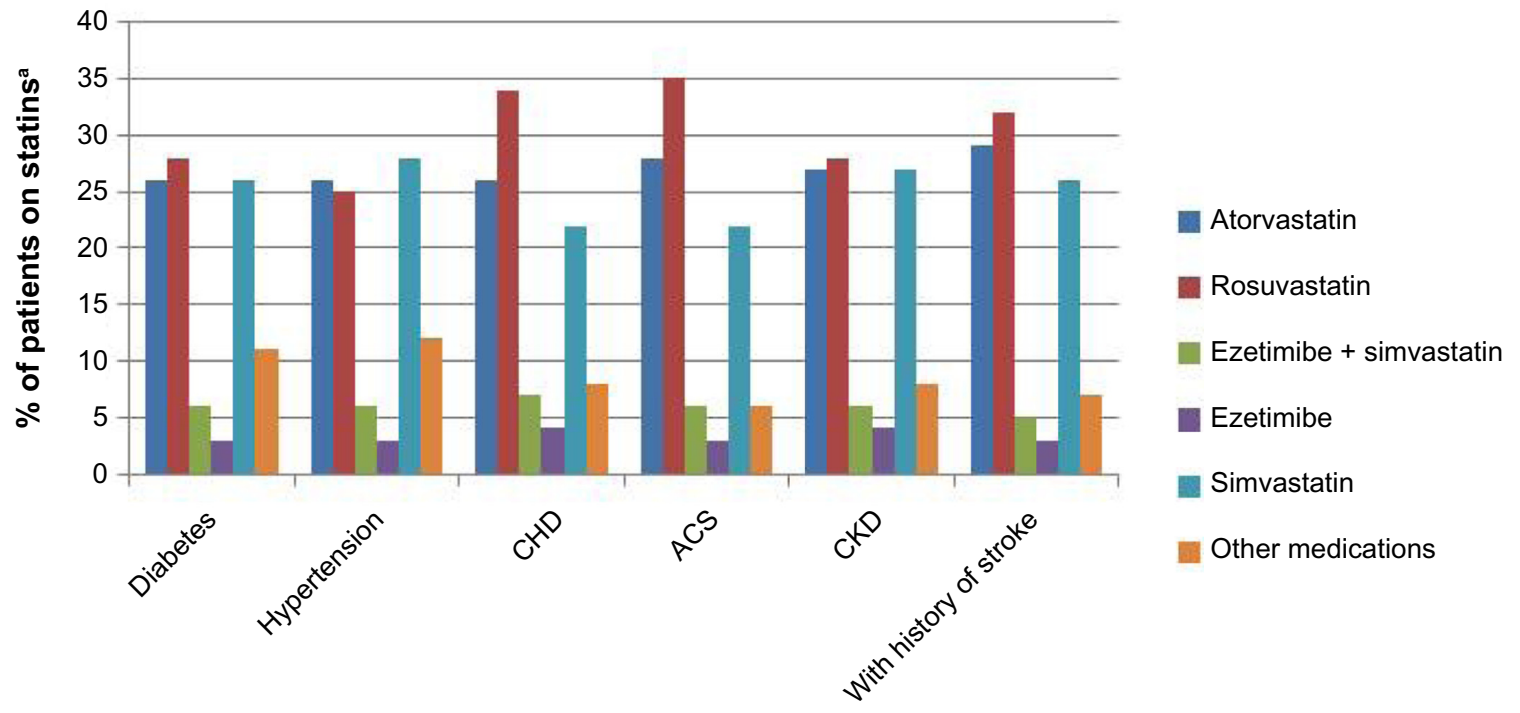

Figure I Patients on statins by concomitant condition.

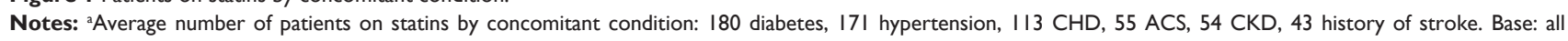
respondents $(n=66)$. Generic rosuvastatin was not available when the study was conducted. Other medications include ezetimibe, fenofibrates, fluvastatin, pravastatin, etc. Abbreviations: ACS, acute coronary syndrome; CHD, coronary heart disease; CKD, chronic kidney disease. 
Table 3 Dyslipidemia patient grouping based on 2013 ACC/AHA guidelines

\begin{tabular}{|c|c|c|c|c|c|c|c|c|}
\hline \multirow[t]{2}{*}{ By specialty } & \multicolumn{2}{|c|}{ Clinical ASCVD } & \multicolumn{2}{|c|}{$\begin{array}{l}\text { Primary LDL } \\
\geq 190 \mathrm{mg} / \mathrm{dL}\end{array}$} & \multicolumn{2}{|c|}{$\begin{array}{l}\text { DM + LDL: } \\
\text { 70-189 mg/dL }\end{array}$} & \multicolumn{2}{|c|}{$\begin{array}{l}\text { Risk of ASCVD } \geq 7.5 \%+ \\
\text { LDL: } 70-189 \mathrm{mg} / \mathrm{dL}\end{array}$} \\
\hline & $\begin{array}{l}\text { Number } \\
\text { of } \\
\text { patients }\end{array}$ & $\begin{array}{l}\% \text { patients } \\
\text { treated with } \\
\text { high-intensity } \\
\text { statin }\end{array}$ & $\begin{array}{l}\text { Number } \\
\text { of } \\
\text { patients }\end{array}$ & $\begin{array}{l}\% \text { patients } \\
\text { treated with } \\
\text { high-intensity } \\
\text { statin }\end{array}$ & $\begin{array}{l}\text { Number } \\
\text { of } \\
\text { patients }\end{array}$ & $\begin{array}{l}\% \text { patients } \\
\text { treated with } \\
\text { high-intensity } \\
\text { statin }\end{array}$ & $\begin{array}{l}\text { Number } \\
\text { of } \\
\text { patients }\end{array}$ & $\begin{array}{l}\% \text { patients } \\
\text { treated with } \\
\text { high-intensity } \\
\text { statin }\end{array}$ \\
\hline$G P(n=3 I)$ & 48 & 42 & 64 & 39 & 114 & 35 & 69 & 38 \\
\hline Cardiologist $(n=20)$ & 133 & 41 & 61 & 28 & 178 & 25 & 105 & 37 \\
\hline $\begin{array}{l}\text { Endocrinologist/ } \\
\text { nephrologist }(n=15)\end{array}$ & 78 & 53 & 55 & 40 & 245 & 47 & 64 & 48 \\
\hline
\end{tabular}

Note: Base: all respondents $(n=66)$.

Abbreviations: ACC/AHA, American College of Cardiology and American Heart Association; ASCVD, atherosclerotic cardiovascular disease; DM, diabetes mellitus; GP, general practitioner; LDL, low-density lipoprotein.

When physicians were asked about their preference of statin prescriptions and its dose for the four categories of patients defined by the ACC/AHA guidelines 2013, a clear resistance was seen to the use of high-intensity statins (Figure 2).

Patients profile for different strengths of atorvastatin and rosuvastatin is described in Table 4. Prescription of $80 \mathrm{mg}$ atorvastatin or $40 \mathrm{mg}$ rosuvastatin was restricted to second or third line treatment option in patients with baseline LDL of $160-189 \mathrm{mg} / \mathrm{dL}$.

\section{Considerations while choosing lipid-lowering agents}

Attributes that influenced the choice of lipid-lowering therapy revealed that effectiveness of statins in terms of reducing a potential CV event and lowering LDL-C, and safety of statins were most important to the physicians.

\section{Discussion}

The present survey on 2013 ACC/AHA guidelines for prevention of ASCVD included a wide range of practitioners involved in treating dyslipidemia in the clinical setting. Guidelines directing clinical practice are an important tool in applying evidence-based medicine to patient care. The 2013 ACC/AHA guidelines for cholesterol treatment focus on individuals in whom LDL-C lowering would provide the maximum benefit in reducing the risk of cardiovascular disease caused by atherosclerosis.

Singapore physicians were still most familiar with the Singapore $\mathrm{MoH} 2006$ lipid guidelines and are continuing to use them, even though they have not yet caught up with the latest international guidelines from the United States and United Kingdom. ${ }^{16}$ Only one in three physicians expressed strong familiarity with the 2013 ACC/AHA guidelines. In accordance with their specialty, cardiologists were most

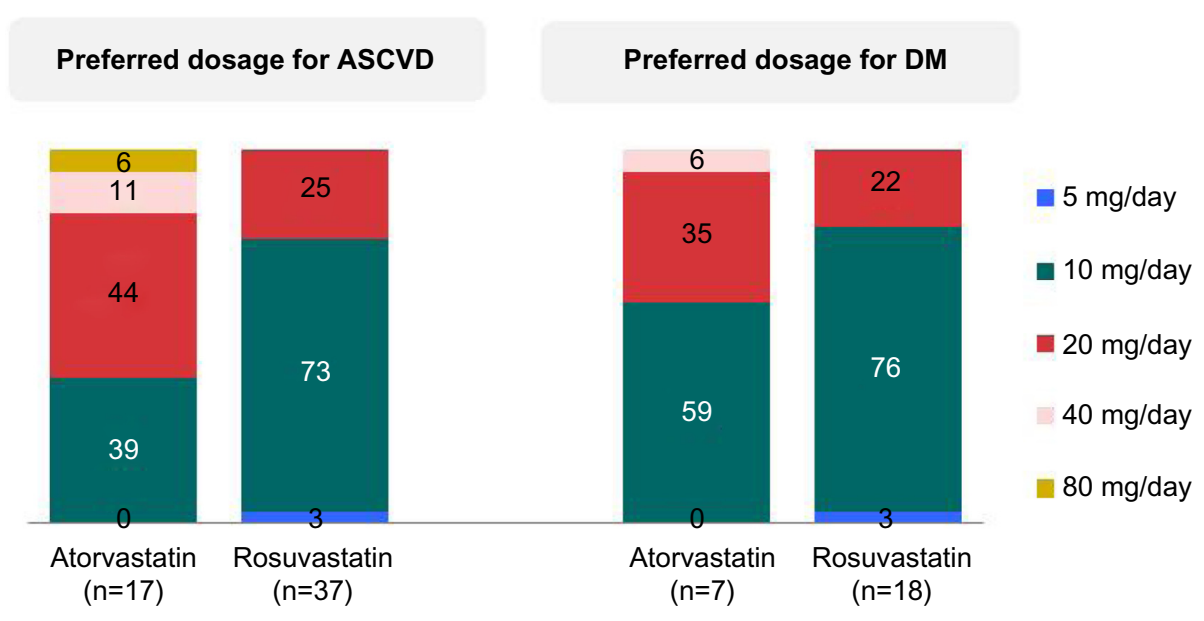

Figure 2 Preferred dosages of atorvastatin and rosuvastatin for ASCVD and DM management.

Notes: Base: all respondents prescribing in the past 3 months. Asked only for branded atorvastatin and branded rosuvastatin. Generic rosuvastatin was not available when the study was conducted.

Abbreviations: ASCVD, atherosclerotic cardiovascular disease; DM, diabetes mellitus. 
Table 4 Patient profile for atorvastatin and rosuvastatin ${ }^{\mathrm{a}}$

\begin{tabular}{lllll}
\hline & Atorvastatin $\mathbf{2 0 - 4 0 ~} \mathbf{~ m g}$ & Atorvastatin $\mathbf{8 0 ~} \mathbf{~ m g}$ & Rosuvastatin $\mathbf{~ 0 - 2 0 ~} \mathbf{~ m g}$ & Rosuvastatin $\mathbf{4 0} \mathbf{~ m g}$ \\
\hline Age & Not a factor & Not a factor & Not a factor & Not a factor \\
Risk factors & ACS & ACS & CHD & ACS \\
& CHD & CHD & & CHD \\
LDL baseline (mg/dL) & $130-159$ & $160-189$ & $130-159$ & $160-189$ \\
& $160-189$ & & $160-189$ & $\geq 50 \%$ \\
LDL target (lower to ...) & $\geq 50 \%$ & $\geq 50 \%$ & $\geq 50 \%$ & Second line \\
Line of treatment & First line & Second line & First line & Third line and above \\
\hline
\end{tabular}

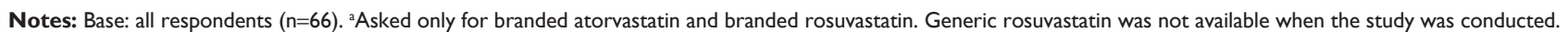
Abbreviations: ACS, acute coronary syndrome; CHD, coronary heart disease; LDL, low-density lipoprotein.

familiar with the 2013 ACC/AHA guidelines followed by the endocrinologist/nephrologists and the GPs. It is also expected that the number of dyslipidemia patients treated by these doctors would be in a similar order.

Doctors who were aware of the 2013 ACC/AHA guidelines disagreed with the definition of high-, moderate-, and low-intensity statin and also disagreed with the use of highintensity statins in the therapy of high-risk individuals. The disagreement with the definition of high-intensity statins may be due to concerns regarding the safety and tolerability of high-dose statins in Asian patients.

Titration of therapy from the recommended starting dose to achieve optimal therapeutic results adds complexity and cost, and patients typically prefer not to return for additional visits. A starting dose that provides the greatest likelihood of reducing the risk of CVD while maintaining the overall safety profile would be a preferred strategy. ${ }^{16}$

According to this survey, the most commonly prescribed statin was rosuvastatin, followed by simvastatin and atorvastatin. Overall the prescription of high-intensity statins was very low.

Also rosuvastatin was prescribed in dyslipidemic patients with diabetes, hypertension, CHD, ACS, CKD, and with a history of stroke, despite lack of clinical outcome data for secondary prevention in these patient populations. ${ }^{19}$

Even though prescription of atorvastatin in primary and secondary prevention of CVD was only second to rosuvastatin in this study, there is a substantial volume of evidence for atorvastatin efficacy in both primary and secondary prevention of cardiovascular events. ${ }^{20}$ Studies showed that relative to simvastatin (in the incremental decrease in end points through aggressive lipid lowering-acute coronary syndromes [IDEAL] trial) and low-dosage atorvastatin (in the treating to new targets trial), intensive atorvastatin therapy $(80 \mathrm{mg} /$ day) reduced the risk of nonfatal myocardial infarction (MI) by $17 \%-22 \%(P \leq 0.02) .{ }^{20}$ The MIRACL (Myocardial Ischemia Reduction with Aggressive Cholesterol Lowering), PROVE-IT (PRavastatin Or atorVastatin Evaluation and Infection Therapy), and IDEAL-ACS (Acute Coronary Syndromes) studies highlighted the benefits of high-dosage atorvastatin therapy started within 24-96 hours, 10 days or 2 months, respectively, of an ACS..$^{20}$ Despite this, the present study revealed some reluctance on the part of clinicians to use high-dose statins.

The use of high-intensity statins in cholesterol treatment is further supported by recommendations made in other guidelines. The National Institute for Health and Care Excellence (NICE) guidelines on lipid modification (July 2014) states that when a decision to prescribe a statin is made, a high-intensity statin should be used. Atorvastatin $20,40,80 \mathrm{mg}$, simvastatin $80 \mathrm{mg}$ and rosuvastatin 10,20 and $40 \mathrm{mg}$ are classified as high-intensity statins. Guidelines recommend atorvastatin $20 \mathrm{mg}$ for primary prevention of CVD and atorvastatin $80 \mathrm{mg}$ for secondary prevention in patients with CVD. ${ }^{21}$ In addition, the revised 2015 American Diabetes Association (ADA) standards of care have adopted recommendations from 2013 ACC/AHA guidelines for cholesterol management in diabetics. They recommend high-dose statins for all diabetic patients with increased cardiovascular risk (eg, LDL-C $>100 \mathrm{mg} / \mathrm{dL}$ [2.6 mmol/L], high blood pressure, smoking, and overweight/obesity) or with overt CVD. ${ }^{22}$

Most physicians in this survey felt that high-intensity stains were not required because low doses of statins achieved sufficient LDL-C reduction and worked well in Asians. Most physicians also believed that Asians are intolerant to high doses of statins. Studies have revealed increased systemic exposure of rosuvastatin in Asians. However, this does not appear to be a class effect among the high-intensity statins, and this finding should be restricted to rosuvastatin only. Physicians 
tend to extrapolate these findings to all statins, which can act as a barrier to prescription of high doses for other statins. ${ }^{23}$ Studies have not identified any difference between Asians and Caucasians in the systemic exposure to atorvastatin. Analysis of data in 310 Asians and 579 Caucasians from 22 single-dose (10-80 mg atorvastatin) studies revealed that dosing considerations for atorvastatin are similar for Asian compared with Caucasian subjects. ${ }^{24}$ Atorvastatin $(10-80 \mathrm{mg})$ is also found to be equally efficacious in the Asian and the white populations..$^{25,26}$

In a meta-analysis of 49 clinical studies involving more than 14,000 patients treated with atorvastatin $(10-80 \mathrm{mg})$ or placebo, a few cases of treatment-related myalgia $(1.4 \%$, $1.5 \%$, and $0.7 \%$ of patients on atorvastatin $10 \mathrm{mg} /$ day, atorvastatin $80 \mathrm{mg} /$ day, and placebo, respectively) and no cases of rhabdomyolysis were reported. Unlike simvastatin, an increased risk of myopathy was not observed for higher doses of atorvastatin. ${ }^{27}$ PLANET I (Prospective Evaluation of Proteinuria and Renal Function in Diabetic Patients With Progressive Renal Disease) and PLANET II (Prospective Evaluation of Proteinuria and Renal Function in Nondiabetic Patients With Progressive Renal Disease) trials showed that high-dose atorvastatin $(80 \mathrm{mg})$ significantly reduced proteinuria with no adverse effects on renal function, whereas rosuvastatin (10 and $40 \mathrm{mg}$ ) significantly worsened renal function, with no reduction in proteinuria. ${ }^{28-30}$ Even though physicians in this study commonly prescribed rosuvastatin and simvastatin to patients, the evidence so far is clearly in favor of the use of atorvastatin (20-80 mg) for primary and secondary prevention of CVD.

This study has some limitations. In this study, only physicians in private practice were surveyed, and this may add bias to our study. Additionally, a small number of physicians were included in this study. Since this study was conducted within a short span (February-May 2014) of the release of ACC/AHA guidelines 2013, it could have had an effect on familiarity with its recommendations.

In summary, clinical practice has long focused on the treatment with statins to achieve LDL-C goals. Acceptance of high-intensity statins like atorvastatin among physicians may increase with better understanding of the wealth of data available for atorvastatin in primary and secondary prevention of ASCVD. Recommendations of the 2013 ACC/AHA guidelines to use high-intensity statin therapy with atorvastatin are further strengthened by its similar efficacy and safety profile in the white and the Asian populations. Embracing these guidelines in clinical practice is expected to provide optimal clinical care to patients.

\section{Acknowledgments}

Special thanks to the management and staff of Kantar Health, Singapore, for their efforts in screening the respondents and carrying out interviews with the eligible respondents. The authors would also like to acknowledge Sciformix Technologies Pvt Ltd, India, for providing editorial and writing support, which was funded by Pfizer.

\section{Disclosure}

Dr Sajita Setia is an employee of Pfizer Pte Ltd, Singapore. Dr Selwyn Sze-Wang Fung is an employee of Pfizer Pte Ltd, Hong Kong. Dr David D Waters has received remuneration for participating in clinical trial committees from Aastrom, Cerenis, CSL Ltd, Merck Schering-Plough, Pfizer, and Sanofi, and has received honoraria for lectures from Pfizer. This study was funded in full by Pfizer.

\section{References}

1. World Health Organization. Cardiovascular Diseases (CVDs), fact sheet updated January 2015. Available from: http://www.who.int/mediacentre/ factsheets/fs317/en/. Accessed March 16, 2015.

2. World Health Organization. Global Status Report on Noncommunicable Diseases 2014. Available from: http://www.who.int/entity/nmh/ publications/ncd-status-report-2014/en/index.html. Accessed March 16, 2015.

3. Ohira T, Iso H. Cardiovascular disease epidemiology in Asia - an overview. Circ J. 2013;77:1646-1652.

4. The Registry of Births and Deaths, Immigration and Checkpoints Authority. Report on Registration of Births and Deaths 2013. Singapore: The Registry of Births and Deaths, Immigration and Checkpoints Authority. Available from: http://www.ica.gov.sg/data/resources/ docs/Media\%20Releases/SDB/Annual\%20RBD\%20Report_2013.pdf. Accessed December 22, 2014

5. Ministry of Health. Disease Burden. Singapore: Ministry of Health; 2012. Available from: https://www.moh.gov.sg/content/moh_web/ home/statistics/Health_Facts_Singapore/Disease_Burden.html. Accessed December 22, 2014.

6. Yoon KH, Lee JH, Kim JW, et al. Epidemic obesity and type 2 diabetes in Asia. Lancet. 2006;368(9548):1681-1688.

7. Smith DG. Epidemiology of dyslipidemia and economic burden on the healthcare system. Am J Manag Care. 2007;13(3):S68-S71.

8. Stamler J, Daviglus ML, Garside DB, Dyer AR, Greenland P, Neaton JD. Relationship of baseline serum cholesterol levels in 3 large cohorts of younger men to long-term coronary, cardiovascular, and all-cause mortality and to longevity. JAMA. 2000;284(3):311-318.

9. Epidemiology and Disease Control Division, Ministry of Health. National Health Survey 2010. Singapore: Epidemiology and Disease Control Division, Ministry of Health, Singapore. Available from: https:// www.moh.gov.sg/content/dam/moh_web/Publications/Reports/2011/ NHS2010\%20-\%20low\%20res.pdf. Accessed March 16, 2015.

10. Yusuf S, Hawken S, Ounpuu S, et al. Effect of potentially modifiable risk factors associated with myocardial infarction in 52 countries (the INTERHEART study): case-control study. Lancet. 2004;364(9438): 937-952.

11. De Caterina R, Zampolli A, Del Turco S, Madonna R, Massaro M. Nutritional mechanisms that influence cardiovascular disease. Am J Clin Nutr. 2006;83(2):S421-S426.

12. Talwalkar PG, Sreenivas CG, Gulati A, Baxi H. Journey in guidelines for lipid management: From adult treatment panel (ATP)-I to ATP-III and what to expect in ATP-IV. Indian J Endocrinol Metab. 2013;17(4): $628-635$. 
13. Grundy SM, Cleeman JI, Merz CN, et al. Implications of recent clinical trials for the National Cholesterol Education Program Adult Treatment Panel III guidelines. Circulation. 2004;110(2):227-239.

14. Waters DD, Brotons C, Chiang CW, et al. Lipid treatment assessment project 2: a multinational survey to evaluate the proportion of patients achieving low-density lipoprotein cholesterol goals. Circulation. 2009;120(1):28-34.

15. Kim HS, Wu Y, Lin SJ, et al. Current status of cholesterol goal attainment after statin therapy among patients with hypercholesterolemia in Asian countries and region: the Return on Expenditure Achieved for Lipid Therapy in Asia (REALITY-Asia) study. Curr Med Res Opin. 2008;24(7):1951-1963.

16. Ministry of Health. Clinical Practice Guidelines: Lipid. Singapore: Ministry of Health; 2006. Available from: https://www.moh.gov.sg/ content/moh_web/home/Publications/guidelines/withdrawn_cpgs.html. Accessed December 22, 2014.

17. Stone NJ, Robinson JG, Lichtenstein AH, et al. 2013 ACC/AHA guideline on the treatment of blood cholesterol to reduce atherosclerotic cardiovascular risk in adults: a report of the American College of Cardiology/American Heart Association Task Force on Practice Guidelines. J Am Coll Cardiol. 2014;63(25 Pt B):2889-2934.

18. Johnson KM, Dowe DA. Accuracy of statin assignment using the 2013 AHA/ACC Cholesterol Guideline versus the 2001 NCEP ATP III guideline: correlation with atherosclerotic plaque imaging. $\mathrm{J} \mathrm{Am} \mathrm{Coll}$ Cardiol. 2014;64(9):910-919.

19. Luvai A, Mbagaya W, Hall AS, Barth JH. Rosuvastatin: a review of the pharmacology and clinical effectiveness in cardiovascular disease. Clin Med Insights Cardiol. 2012;6:17-33.

20. Arca M, Gaspardone A. Atorvastatin efficacy in the primary and secondary prevention of cardiovascular events. Drugs. 2007;67(Supp1 1): 29-42.

21. National Institute for Health and Care Excellence. Lipid modification: cardiovascular risk assessment and the modification of blood lipids for the primary and cardiovascular disease. NICE clinical guideline 181; 2014. Available from: http://www.nice.org.uk/guidance/cg181. Accessed December 22, 2014.
22. American Diabetes Association. Cardiovascular disease and risk management. Sec 8. In Standards of Medical Care in Diabetes - 2015. Diabetes Care. 2015;38 (Suppl 1):S49-S57.

23. Lee E, Ryan S, Birmingham B, et al. Rosuvastatin pharmacokinetics and pharmacogenetics in white and Asian subjects residing in the same environment. Clin Pharmacol Ther. 2005;78(4):330-341.

24. Gandelman K, Fung GL, Messig M, Laskey R. Systemic exposure to atorvastatin between Asian and Caucasian subjects: a combined analysis of 22 studies. Am J Ther. 2012;19(3):164-173.

25. Jones PH, McKenney JM, Karalis DG, Downey J. Comparison of the efficacy and safety of atorvastatin initiated at different starting doses in patients with dyslipidemia. Am Heart J. 2005;149(1):e1.

26. Panelo AA, Fernando RE, Sy RG, et al. The efficacy and safety of atorvastatin 10, 20, 40 and $80 \mathrm{mg}$ in Filipino dyslipidemic patients: the lipitor dose-response study in Filipinos [abstract]. Philipp J Intern Med. 2005;43(5):293-300. Available from: http://pimedicus.upm.edu. ph/index.php?fetch_detailed=5233\&KeyWords $=\&$ Media $=\&$ Heading $=$ $\&$ Operator $=\&$ offset $=\&$ total $=\&$ limit $=\&$ marc. Accessed December 24 , 2014.

27. Hu M, Cheung BM, Tomlinson B. Safety of statins: an update. Ther Adv Drug Saf. 2012;3(3):133-144.

28. Keller DM. PLANET I and II: Atorvastatin beats rosuvastatin for protecting kidneys in diabetic and nondiabetic patients. Medscape. July 05, 2010. Available from: http://www.medscape.com/viewarticle/790656. Accessed December 22, 2014.

29. De Zeeuw D, Anzalone DA, Cain VA, et al. Renal effects of atorvastatin and rosuvastatin in patients with diabetes who have progressive renal disease (PLANET I): a randomised clinical trial. Lancet Diabetes Endocrinol. 2015;3(3):181-190.

30. Campese VM. Statins and the kidney: friend or foe? Lancet Diabetes Endocrinol. 2015;3(3):161-162.
Vascular Health and Risk Management

\section{Publish your work in this journal}

Vascular Health and Risk Management is an international, peerreviewed journal of therapeutics and risk management, focusing on concise rapid reporting of clinical studies on the processes involved in the maintenance of vascular health; the monitoring, prevention and treatment of vascular disease and its sequelae; and the involvement of

\section{Dovepress}

metabolic disorders, particularly diabetes. This journal is indexed on PubMed Central and MedLine. The manuscript management system is completely online and includes a very quick and fair peer-review system, which is all easy to use. Visit http://www.dovepress.com/ testimonials.php to read real quotes from published authors. 